\title{
Preface
}

\section{Anthropogenic influences on the environmental status of remote mountain lakes}

\author{
David M. Livingstone* \\ Water Resources Department, Swiss Federal Institute of Aquatic Science and Technology (Eawag), \\ Überlandstrasse 133, CH-8600 Dübendorf, Switzerland
}

The special feature in this issue of Aquatic Sciences is based on work conducted as an integral part of the European Union Project "EMERGE" (European Mountain Lake Ecosystems: Regionalisation, Diagnostics and Socio-Economic Evaluation). EMERGE, which ran from 2000 to 2003 and was funded mainly by the European Commission within its Framework Programme 5 (contract EVK1-CT-1999-00032), was one of the larger EU FP5 projects devoted to environmental and climate research, with 26 partner institutes from 15 European countries sharing a total budget of $€ 5.7$ million. The principal aims of the EMERGE project were to assess the status of remote mountain lake ecosystems throughout Europe, to evaluate the findings of this assessment in ecological, environmental and socio-economic terms, and to provide decisionmakers with an overall understanding of remote mountain lakes to allow them to take appropriate policy and management decisions to ensure the future sustainability of these remote aquatic ecosystems. More than 1000 remote lakes, deemed to be essentially unaffected by local anthropogenic influences, were sampled during the EMERGE project. These lakes, all above the tree-line, are located all over Europe. They are scattered throughout the Norwegian mountains, northern Finland, the Scottish Highlands, and the Spanish Pyrenees; along the arc of the Alps from France through Switzerland, Italy and Austria to the Julian Alps of Slovenia; along the Carpathians from the Slovakian and Polish Tatras to the Retezat Mountains of Romania; and in the Rila Mountains of western Bulgaria.

Any analysis of the current environmental and ecological status of lakes must include a historical compo-

* Corresponding author phone: +41 4482355 40; fax: +41 4482352 10; e-mail: living@eawag.ch Published Online First: September 8, 2005 nent that will allow at least a rudimentary comparison of current with past conditions. In EMERGE, this historical component was supplied by making comparative analyses of pre-industrial and modern conditions based on biotic remains, such as diatoms, chironomids and cladocera, obtained from sediment cores. Diatoms, for instance, are known to react sensitively to changes in their environment, allowing changes in diatom assemblages through time to be interpreted in environmental terms. The best-known example of this is the link between diatom species composition and lake water $\mathrm{pH}$, with a decrease in $\mathrm{pH}$ resulting in a higher abundance of acidophilous diatom species (e.g., Psenner and Schmidt, 1992). Clarke et al. (2005) analyse the changes occurring in diatom assemblages over approximately the past $150 \mathrm{yr}$ in mountain regions across Europe by comparing "top" (modern) and "bottom" (pre-industrial) samples taken from short sediment cores obtained from 209 remote mountain lakes, and applying empirical ordination techniques to relate the changes in diatom species composition that they find to changes in environmental driving variables. They find a change in diatom assemblage composition to have occurred in several European mountain regions over the last $150 \mathrm{yr}$, with particularly substantial changes having occurred in the Central Swiss Alps and the Pyrenees. In most lakes, the number of planktonic diatom species was found to have increased. However, pre-industrial and modern lake water $\mathrm{pH}$ values inferred for each lake region from the diatom assemblages were found to differ only slightly, implying that other driving variables, such as changes in nutrient loading, ice phenology and erosion brought about by climate warming, were responsible for the changes in the diatom assemblages found.

In accordance with the European Union Water Quality Directive (European Union, 2000), one important goal 
of the EMERGE project was to assess the extent of acidification of remote mountain lakes and high-latitude lakes throughout Europe. Curtis et al. (2005a) apply the first-order acidity balance model to 300 such lakes in nine European lake districts to assess the extent to which the critical load of atmospheric pollutants (sulphur and nitrogen) contributing to lake acidification is exceeded. In four of the nine lake districts (the Alps of Piedmont and Ticino, the Pyrenees, the Retezat Mountains and the Tatras), they find that a critical acid neutralising capacity (ANC) of $0 \mu \mathrm{eq} \mathrm{L} \mathrm{L}^{-1}$ was exceeded in at least one lake, implying that these lake districts are the most seriously affected by acidification. In all nine lake districts, however, a stricter critical ANC of $20 \mu \mathrm{eq} \mathrm{L}{ }^{-1}$ was exceeded in at least one lake, despite the fact that the geological setting of some of these lake districts is predominantly calcareous. Northern Finland, the Rila Mountains, Scotland and the Tyrolean Alps had the lowest proportion of lakes that exceeded the stricter critical ANC. Both sulphur and nitrogen are shown to contribute to critical load exceedance, although the relative importance of the two depends on the lake district. Curtis et al. (2005a) provide, for the first time, evidence for critical load exceedance in the Retezat Mountains of Romania and the Rila Mountains of Bulgaria.

Under the Convention on Long-Range Transboundary Air Pollution, policies aimed at reducing the emission of atmospheric pollutants in Europe are based on critical loads established for the standard $50 \mathrm{~km} \times 50 \mathrm{~km}$ deposition grid squares of the European Monitoring and Evaluation Programme (EMEP). Because high mountain lakes react sensitively to atmospheric pollution, the presence of such lakes within an EMEP grid square would be expected to result in extremely low critical acid deposition loads applying to the entire grid square, resulting in atmospheric pollution emission targets being set at a level that would be very difficult to achieve. Curtis et al. (2005b) analyse the effect that the inclusion of high mountain lakes in EMEP grid squares has, and show that this effect does not correspond to expectations. On the one hand, the proportion of most EMEP grid cells accounted for by mountain lake catchment areas is relatively small. On the other hand, because of their low-sensitivity geological setting and remoteness from sources of air pollution, critical loads for some mountain lake districts are high in comparison to the low depositional loads occurring there. Thus the inclusion of such lakes in EMEP grid squares would actually result in a relaxation of emission abatement requirements rather than a tightening-up. On the basis of their study, Curtis et al. (2005b) conclude that the inclusion of data from mountain lakes is unlikely to bias emission targets for atmospheric pollution, but also make several specific recommendations regarding the collection of critical load data for mountain lakes, including careful site selection, data screening for local geolog- ical sources of acidity, and the advisability of utilising local deposition data in mountainous areas wherever possible to reduce uncertainty because of altitudinal effects on deposition.

Because they are otherwise relatively undisturbed, the ecosystems of remote mountain lakes are ideal for obtaining information on the fate of pollutants transported over long distances in the atmosphere. In addition to investigating the effects of atmospheric pollution on lake acidification, the occurrence of persistent organic pollutants (POPs) in remote mountain lakes was also examined within the EMERGE project. POPs, which are toxic, volatile and chemically stable, are distributed widely by long-distance atmospheric transport, and can be easily detected in high mountain lakes. Fernández et al. (2005) describe a comprehensive comparative analysis of POPs (including hexachlorocyclohexanes, endosulfans, hexachlorobenzene, DDTs, polychlorinated biphenyls and polycyclic aromatic hydrocarbons) in two lakes in the Pyrenees and the Tatras. They discover that those POPs that are no longer being actively deposited because they are now banned in most of Europe show similar, relatively low concentrations in both lakes, whereas POPs that are still in use, and therefore currently being emitted, show significant differences in concentration between the lakes. These differences reflect differences in the sources of pollution at the two sites that are consistent with a higher impact of agricultural activities on the Pyrenees site and a higher impact of industrial pollution on the Tatras site, although in both cases the pollutants arrive at the sites via long-range atmospheric transport. Concentration profiles for dissolved POPs of low molecular weight show a decrease in concentration with depth that is consistent with their introduction into the lakes via gas exchange at the air-water interface. In contrast, the concentrations of POPs of higher molecular weight that tend to be associated with suspended particles are independent of depth, suggesting an efficient downward transport of the latter within the water column.

A significant requirement of EU Framework 5 was the incorporation and integration of a socio-economic component into each project, with the aim of ensuring that the social and economic implications of the scientific research conducted within the project could be made available to policy-makers. In the case of EMERGE, this consisted of conducting a socio-economic and policy analysis of measures to mitigate the effects of air pollution on remote mountain lakes (Bateman et al., 2004). One aspect of this involved assessing preferences, values and policy attitudes towards remote mountain lakes by people of different social, economic and cultural backgrounds and from different geographical regions, with the aim of providing a cost-benefit analysis of policies designed to protect such lakes. Since markets do not generally exist for the exchange of environmental goods, it is 
difficult, if not impossible, to put a market value on goods such as the ecological quality of remote mountain lakes. Solving this problem requires a non-market valuation technique that is capable of estimating the benefit of an environmental resource in monetary terms not only to those who directly use the resource, but also to those who value the mere existence of the resource without making direct use of it. In the case of remote mountain lake ecosystems, this indirect, non-use component can be assumed to be of relatively high importance, necessitating the employment of a so-called "stated preference" approach designed to estimate the economic value of an environmental resource by eliciting individuals' willingness to pay for public intervention to improve or to protect the resource. The commonly-used contingent valuation method uses such an approach to estimate the benefits of environmental goods by constructing a hypothetical market for changes in the quantity or quality of the goods, and eliciting individuals' willingness to pay for an improvement in the provision of the goods or for the avoidance of a loss in their provision. However, the validity and usefulness of the results of contingent valuation analyses is controversial, with some uncertainty existing as to whether they deliver economically relevant information or are determined primarily by economically irrelevant psychological factors. Bateman et al. (2005) use the concrete example of the problem of the acidification of remote mountain lakes in the Scottish Highlands by largescale air pollution to examine whether the responses to a contingent value survey conform to economic or psychological theories of choice. Their results support the case for using contingent valuation methods to contribute economically relevant information to environmental policymakers, and also suggest that qualitative pre-survey focus group investigations can improve the efficiency of contingent valuation surveys. With respect to the specific case of the acidification of remote mountain lakes in Scotland, the results of the study suggest that in the UK, willingness to pay to protect a minimum number of these lake ecosystems - about five - from further ecological deterioration is likely to be economically significant. However, the marginal willingness to pay for the protection of more than this minimum number of lakes is minimal. In addition, the survey responses for willingness to pay for improvements to the current ecological condition of these lakes, as opposed to the mere prevention of further ecological deterioration, fail economic consistency tests, indicating weak, economically inadmissible preferences.

The articles published in this special feature represent only a small selection of the wide range of research on remote mountain lakes that was conducted within the EMERGE programme. Nevertheless, they illustrate well the fact that even in such remote aquatic ecosystems, far from direct, local anthropogenic influence, the all-perva- sive influence of man on the global environment is making itself felt. Remote mountain lakes have experienced detectable changes in their biota since pre-industrial times. The long-range atmospheric transport and subsequent deposition of sulphur and nitrogen is resulting in the acidification of such lakes, while persistent organic pollutants originating from agriculture and industry, also transported long distances from their sources before final deposition, are found in significant concentrations in the water column. These undesirable anthropogenic influences on the environmental status of remote mountain lakes, a by-product of global-scale economic development, make it necessary to monitor and protect these unique ecosystems. Ultimately, however, it is policy decisions based on the public perception of the utility of remote mountain lake ecosystems in monetary terms that will determine their future.

\section{References}

Bateman, I. J., P. Cooper, S. Georgiou, S. Navrud, G. L. Poe, R. C. Ready, P. Riera, M. Ryan and C. A. Vossler, 2004. Scope sensitivity tests for preference robustness: an empirical examination of economic expectations regarding the economic valuation of policies for reducing acidity in remote mountain lakes. CSERGE Working Paper EDM 04-03, Centre for Social and Economic Research on the Global Environment, University of East Anglia, UK, 85 pp.

Bateman, I. J., P. Cooper, S. Georgiou, S. Navrud, G. L. Poe, R. C. Ready, P. Riera, M. Ryan and C. A. Vossler, 2005. Economic valuation of policies for managing acidity in remote mountain lakes: examining validity through scope sensitivity testing. Aquatic Sciences 67: 274-291.

Clarke, G., M. Kernan, A. Marchetto, S. Sorvari and J. Catalan, 2005. Using diatoms to assess geographical patterns of change in high-altitude European lakes from pre-industrial times to the present day. Aquatic Sciences 67: 224-236.

Curtis, C. J., I. Botev, L. Camarero, J. Catalan, D. Cogalniceanu, M. Hughes, M. Kernan, J. Kopáček, A. Korhola, R. Psenner, M. Rogora, E. Stuchlík, M. Veronesi and R. Wright, 2005a. Acidification in European mountain lake districts: a regional assessment of critical load exceedance. Aquatic Sciences 67: 237251.

Curtis, C. J., M. Posch, P. Casals-Carrasco, J. Catalan, M. Hughes, M. Kernan and M. Ventura, 2005b. The significance of European high mountain lakes in critical load distributions at the EMEP grid scale. Aquatic Sciences 67: 252-262.

European Union 2000. Directive 2000/60/EC of the European Parliament and of the Council of 23 October 2000 establishing a framework for Community action in the field of water policy. Official Journal L 327: 1-73.

Fernández, P., G. Carrera and J. O. Grimalt, 2005. Persistent organic pollutants in remote freshwater ecosystems. Aquatic Sciences 67: 263-273.

Psenner, R. and R. Schmidt, 1992. Climate-driven pH control of remote alpine lakes and effects of acid deposition. Nature 356: 781-783. 